Medicare Payment Systems: \title{
A Look Back and a Look Forward
}

\author{
Kathleen Dianne Schaum* \\ Kathleen D. Schaum \& Associates, Inc., Lake Worth, Florida.
}

Medicare is the major payer for patients with chronic wounds. Over the past 50 years, the Medicare payment systems have undergone numerous changes. At the beginning of the Medicare program, providers were paid based on feefor-service. In 1997, many of the Medicare payment systems were converted to prospective payment systems (PPSs). Currently, Medicare is conducting many demonstration payment programs to provide the best quality outcomes, at the lowest total cost of care (not necessarily the lowest cost product or procedure), and with patient satisfaction. While the demonstration payment programs are being tested, providers may receive parallel Medicare payments: payment through current PPS and through the demonstration payment program. Wound care providers and manufacturers need to prepare now for the future payment systems.

\section{INTRODUCTION}

"MONEY MAKES THE WORLD go around" is an old adage that is still true today. It doesn't matter whether you are a restaurant, a manufacturer, a hospital, a Congressman, a professor, a bus driver, a scientist, a nurse, a physical therapist, a physician, or any other U.S. citizen or business: everyone needs a source of income! Therefore, it should not be a surprise to learn that one of the most frequently asked questions by wound care device/drug/biologics scientists, manufacturers, facilities, and professionals is: "How much will I be paid if I develop, manufacture, or use this for the care of wound care patients?" Because most patients with chronic wounds are of Medicare age, everyone is particu- larly interested in the Medicare payment programs.

\section{DISCUSSION \\ Medicare payment in the beginning}

When Medicare first began, the government paid itemized bills for wound care patients, much like U.S. consumers pay for their groceries: more groceries in the cart $=$ a higher grocery bill; higher priced groceries in the cart=a higher grocery bill. In fact, this author remembers when every patient received a urinalysis and chest X-ray when they were admitted into a hospital, even if their medical problem did not require those diagnostic tests! In those days, hospitals did not have incentives to provide cost-effective care: more services and higher cost

Information regarding coding, coverage, and payment is provided as a service to our readers. Every effort has been made to ensure the accuracy of the information. Providers, suppliers, and manufacturers are responsible for case-by-case assessment, documentation, and justification of medical necessity. However, Mary Ann Liebert, Inc., and the author do not represent, guarantee, or warranty that the coding, coverage, and payment information is error-free and/or that payment will be received. The ultimate responsibility for verifying coding, coverage, and payment information accuracy lies with the reader.

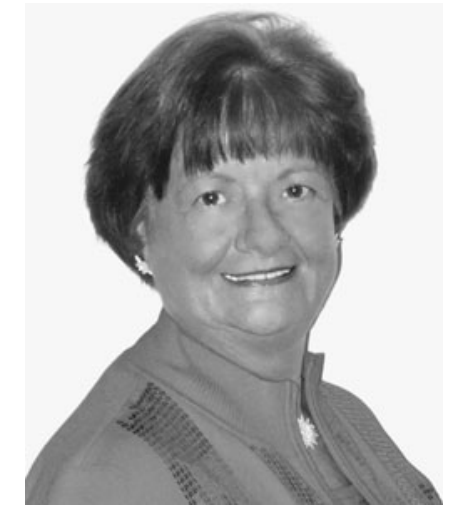

Kathleen Dianne Schaum, MS

Submitted for publication June 30, 2013. Accepted in revised form September 3, 2013.

${ }^{*}$ Correspondence: Kathleen D. Schaum \& Associates, Inc., 6491 Rock Creek Drive, Lake Worth, FL 33467 (e-mail: kathleendschaum@ bellsouth.net). 
services $=$ higher Medicare payments. In addition, hospitals were paid additional sums of money when they purchased new equipment and new furnishings such as high quality support surfaces. It was not uncommon for patients with chronic wounds to remain hospitalized for many weeks, and in some instances, for many months.

\section{Medicare prospective payment systems}

To curb runaway hospital costs, the Medicare program began paying hospitals a flat fee for the entire patient stay. If the hospital was able to discharge the patient before the hospital expended the Medicare payment, the hospital was allowed to keep the extra money. If the hospital spent more than the Medicare payment, the hospital was required to absorb those costs. See Table 1 for a description of the hospital Medicare Severity-Adjusted DiagnosisRelated Groups (MS-DRG) payment system.

The hospitals learned to quickly discharge patients to other sites of care, such as skilled nursing facilities (SNFs), and to home under the care of home

Table 1. Overview of current Medicare payment systems

\begin{tabular}{|c|c|c|}
\hline Provider & Medicare Payment System & Description \\
\hline \multirow[t]{2}{*}{$\begin{array}{l}\text { DME suppliers (for patients at home } \\
\text { or in an SNF during Medicare } \\
\text { Part B covered stays) }\end{array}$} & DMEPOS Fee Schedule & $\begin{array}{l}\text { HCPCS codes are assigned to many medical devices. Every state's DME MAC assigns each } \\
\text { HCPCS code a predetermined rate on their DMEPOS Fee Schedule, unless the product } \\
\text { is part of the competitive bidding program. }\end{array}$ \\
\hline & Competitive Bidding Rate ${ }^{1}$ & $\begin{array}{l}\text { When the product is part of the competitive bidding program, the new, lower payment } \\
\text { amounts, resulting from the competition, are paid instead of the Medicare DMEPOS fee } \\
\text { schedule amounts. }\end{array}$ \\
\hline $\mathrm{HHAs}^{2}$ & $\mathrm{HHRG}^{2}$ & $\begin{array}{l}\text { HHAs use a standardized assessment tool (OASIS) to define the patient's medical and } \\
\text { therapy needs for each 60-day episode-of-care. Based on the resources identified (via } \\
\text { OASIS) to care for each patient, that patient is assigned to an HHRG for each 60-day } \\
\text { episode-of-care. The MACs pay the HHRG rate, which includes all labor and all routine } \\
\text { supplies. MACs pay a small additional amount for specific nonroutine supplies, such as } \\
\text { surgical dressings. THE HHRG payment does not include drugs, biologics, and DME } \\
\text { (e.g., negative pressure and pressure relief devices). }\end{array}$ \\
\hline \multirow[t]{3}{*}{ HOPDs } & $\mathrm{OPPS}^{3}$ & $\begin{array}{l}\mathrm{CPT}^{\circledR} \text { codes and modifiers identify clinic visits and procedures performed in HOPDs. These } \\
\text { codes are tracked to APC groups, based on the level of resources required to perform } \\
\text { that procedure and/or service. MACs pay predetermined rates for each APC group. The } \\
\text { APC payment includes all supplies, such as wound care dressings and compression } \\
\text { bandage systems. }\end{array}$ \\
\hline & $\mathrm{ASP}^{4}$ & $\begin{array}{l}\text { HCPCS codes identify separately payable drugs and biologics that are used in HOPDs. } \\
\text { MACs pay the rates published in the ASP file, which is updated quarterly based on data } \\
\text { submitted to Medicare by manufacturers. }\end{array}$ \\
\hline & $\begin{array}{l}\text { Temporary pass-through } \\
\text { code payment }\end{array}$ & $\begin{array}{l}\text { Transitional "pass-through codes" identify certain new devices, drugs, and biologicals that } \\
\text { are used in HOPDs. MACs pay temporary rates (for } 2-3 \text { years) for these products, while } \\
\text { CMS collects data to determine how to incorporate payment for the new technologies } \\
\text { into existing or new APC groups. }\end{array}$ \\
\hline Hospitals & MS-DRG ${ }^{5}$ & $\begin{array}{l}\text { Each hospitalized patient's ICD-9-CM diagnosis or procedure code is tracked to a MS-DRG } \\
\text { group. MACs pay hospitals a predetermined lump sum payment for each MS-DRG. The } \\
\text { payment includes all medical care, procedures, surgeries, supplies, drugs, and devices. }\end{array}$ \\
\hline \multirow[t]{2}{*}{$\begin{array}{l}\text { QHPS (e.g., physicians, podiatrists, } \\
\text { nurse practitioners, physician } \\
\text { assistants, clinical nurse specialists) }\end{array}$} & MPFS $^{6}$ & $\begin{array}{l}\text { All work performed by physicians is defined by CPT codes and modifiers, which are } \\
\text { assigned relative value units by the American Medical Association. The relative value } \\
\text { units are converted to Medicare payment rates on the MPFS: the payment rates are } \\
\text { usually higher when QHPs provide services in their offices because they are responsible } \\
\text { for the office practice expenses, which include surgical dressings, supplies, etc. } \\
\text { NOTE: OHPs may receive a separate payment for casting and strapping supplies when they } \\
\text { report the HCPCS code(s) for these products. }\end{array}$ \\
\hline & $\mathrm{ASP}^{4}$ & $\begin{array}{l}\text { Drugs and biologicals not paid on a cost or prospective payment basis are paid based on } \\
\text { the ASP methodology, and payment to QHPs is } 106 \text { percent of the ASP. }\end{array}$ \\
\hline $\begin{array}{l}\text { SNFs (for Medicare Part A } \\
\quad \text { covered stays—up to } 100 \text { days) }\end{array}$ & RUGs & $\begin{array}{l}\text { SNFs evaluate each patient with a standardized assessment tool, called MDS, on the 5th, } \\
\text { 14th, 30th, 60th, and 90th days. Based on the resources identified (via MDS) to care for } \\
\text { each patient, that patient's care is assigned to a RUG for that time period. The RUG } \\
\text { payment must cover room and board, labor, supplies, drugs, and equipment. } \\
\text { NOTE: Medicare only pays for SNF care up to } 100 \text { days. }\end{array}$ \\
\hline
\end{tabular}

DME, durable medical equipment; DMEPOS, durable medical equipment, prosthetics/orthotics, and supplies; SNF, skilled nursing facility; HHAs, home health agencies; HHRG, home health resource group; OASIS, Outcome and Assessment Information Set; HOPDs, hospital-based outpatient wound care departments; OPPS, Outpatient Prospective Payment System; APC, Ambulatory Payment Classification; MAC, Medicare Administrative Contractor; ASP, Average Sales Price; CMS, Centers for Medicare \& Medicaid Services; MS-DRG, Medicare Severity-Adjusted Diagnosis Related Groups; QHPs, qualified healthcare professionals; MPFS, Medicare Physician Fee Schedule; RUGs, resource utilization groups; MDS, minimum data set; HCPCS, Health Care Procedure Coding System; ICD-9CM, International Classification of Diseases, Ninth Edition, Clinical Modification. 
health agencies (HHAs). This created more business for the durable medical equipment (DME) suppliers who provided products such as surgical dressings to patients in SNFs and in their homes. These early hospital discharges also encouraged the development of other sites of care such as long-term care hospitals (LTCHs), comprehensive outpatient rehabilitation facilities (CORFs), and hospital-based outpatient wound care departments (HOPDs). All of these sites of care, as well as the physicians, were paid like the hospitals were originally paid: based on their costs and their charges.

Within 10 years, the Medicare program was paying the hospitals less, but the hospitals were doing very well because they were quickly discharging patients to the other sites of care and not spending all the money that Medicare paid them. And you guessed it; Medicare was now facing even bigger payments in all the other sites of care and to all the other providers such as physicians, HOPDs, and DME suppliers. To combat these runaway costs, the Balanced Budget Act (BBA) of 1997 became a public law. The BBA created a unique Prospective Payment System (PPS) for each site of care. See Table 1 for a description of the various PPSs. ${ }^{1-6}$ Each PPS attempted to control Medicare's costs by paying lump sums of money to the sites of care, which caused each provider to manage their costs.

\section{Medicare payment projects to provide quality, low cost, and patient satisfaction}

Within another 10 years, two major phenomena occurred:

1. The sites of care and providers learned how to manage their costs by shifting patients to other sites of care. For example:

a. Hospitals discharged patients as quickly as possible before they expended their Medicare DRG payment.

b. HHAs taught patients and their caregivers to manage their care so they could minimize the number of nurse visits: labor is the largest expenditure in the Medicare HHRG payment.

c. Various sites of service, such as HOPDs, physician offices, HHAs, learned to write orders for DME that could be supplied by the DME supplier.

2. The baby boomers, who were expected to live longer than their parents and grandparents, were starting to enroll into the Medicare program. To prevent the Medicare program from going bankrupt, the government, once again, is forced to refine the
Medicare payment programs. To identify the best overall payment programs, the Centers for Medicare \& Medicaid Services (CMS) is partnering with healthcare systems and providers to try various demonstration projects that will hopefully provide high quality care, at the lowest total cost of care as the patients move across the continuum of care, and with the greatest patient satisfaction. See Table 2 for some examples of those demonstration Medicare payment projects, which are currently undergoing testing. ${ }^{7-12}$

Most of the demonstration Medicare payment projects continue to pay the healthcare systems and/or physicians under the PPS and to pay an additional amount if the providers reduce the government's expenditures for the patients' total cost of care, while at the same time providing high quality care and patient satisfaction. This author refers to these dual payments systems as the "parallel paths to reimbursement": Medicare PPS and Medicare demonstration projects at the same time.

Therefore, healthcare providers, professionals, and manufacturers must learn to "think out of the box" and focus on reinventing their work into case management practices, creating clinical practice guidelines that can be followed across the continuum of care, and writing unique patient plans of care that will follow the chronic wound care patients as they move horizontally through the various sites of care. For example, a health system may stop rewarding physicians and HOPD program directors for increasing the volume of patients seen in the HOPD and may start rewarding them to case manage patients with wounds across the continuum of care. The health system will expect the wound care case management team to create and manage a unique care plan for each patient that will achieve (1) the highest quality outcome that is possible for that particular patient, (2) the lowest cost of care (not necessarily the lowest cost product or procedure), and (3) patient satisfaction.

Wound care professionals must be proactive and approach their healthcare systems with innovative wound care case management programs that can follow the patients throughout the continuum of care. They must also negotiate new methods of performance measurement: they should no longer be paid based on the volume of services performed. Wound care manufacturers must also be proactive by conducting and publishing studies that will show 
Table 2. Partial list of demonstration Medicare payment programs

\begin{tabular}{l} 
Demonstration Payment Program \\
\hline $\mathrm{ACO}^{7}$ \\
Groups of doctors, hospitals, and other \\
healthcare providers, who come together \\
voluntarily to give coordinated high quality \\
care to their Medicare patients. The goal \\
of coordinated care is to ensure that patients, \\
especially the chronically ill, get the right care \\
at the right time, while avoiding unnecessary \\
duplication of services and preventing medical \\
errors.
\end{tabular}

Organizations enter into payment arrangements that include financial and performance accountability for episodes of care, which may lead to higher quality, more coordinated care at a lower cost to Medicare.
Advance Payment ACO Model ${ }^{9}$

Medicare Shared Savings Model ${ }^{10}$

Retrospective acute care

Pioneer ACO Model ${ }^{8}$

Retrospective acute care
hospital stay only
Retrospective acute care hospital
stay plus post-acute care

Retrospective post-acute care only

Acute care hospital stay only
Description

At first, Medicare will share savings based on previous CMS expenditures for the group of patients aligned to the Pioneer ACO.

In year three, those Pioneer ACOs that have shown savings over the first 2 years will be eligible to move to a population-based payment model. Population-based payment is a per-beneficiary per month payment amount intended to replace some or all of the ACO's FFS payments with a prospective monthly payment

Medicare will make advance payments to physician-based and rural providers who have come together voluntarily to give coordinated high quality care to the Medicare patients they serve. Through the Advance Payment ACO Model, selected participants will receive upfront and monthly payments, which they can use to make important investments in their care coordination infrastructure. These payments will be recouped from the shared savings they subsequently earn.

Participating ACOs will receive three types of payments:

- An up-front, fixed payment: each ACO will receive a fixed payment.

- An up-front, variable payment: each ACO will receive a payment based on the number of its historically assigned beneficiaries.

- A monthly payment of varying amount depending on the size of the ACO: each ACO will receive a monthly payment based on the number of its historically assigned beneficiaries.

Medicare will reward ACOs that lower their growth in healthcare costs, while meeting performance standards on quality of care and putting patients first by

- Promoting accountability for the care of Medicare FFS beneficiaries

- Requiring coordinated care for all services provided under Medicare FFS

- Encouraging investment in infrastructure and redesigned care processes

Medicare will pay the hospital a discounted IPPS rate. The hospital will pay the physicians under their traditional fee schedules. Both hospitals and physicians will be permitted to share gains from better coordination of care.

Medicare will make one payment for an episode of care (inpatient stay plus postacute care for either 30,60 , or 90 days after hospital discharge) that must cover the cost for the inpatient stay, the physicians' services, related readmissions, and postacute care providers (e.g., SNFs, HHAs), and ancillary services (such as diagnostic tests, DME and supplies)

Medicare will make one payment for all postacute care (for a minimum of 30,60 , or 90 days) following an inpatient stay. That payment must cover the physician, SNF, inpatient rehabilitation facility, long-term care hospital, diagnostic tests, DME and supplies, etc.

Medicare will make one payment to the hospital for all services furnished by the hospital, by the physicians, by other practitioners during the inpatient stay. This payment will also have to cover related readmissions for 30 days after hospital discharge.

Medicare will pay a monthly care management fee to selected primary care practices their FFS Medicare beneficiaries.

At first the payment will be per-beneficiary per month. In later years, the primary care practices will be eligible to share in any Medicare savings. They will also receive payments from other participating payers such as private payers and Medicare Advantage Plans.
CPC Initiative ${ }^{12}$

Medicare will work with commercial and state payments to primary care doctors who better coordinate care for their patients.

ACO, Accountable Care Organizations; FFS, fee-for-service; IPPS, Inpatient Prospective Payment System; CPC, comprehensive primary care; BPCI, Bundled Payments for Care Improvement Initiative.

wound care professionals and payers how their products and procedures can help them achieve their quality outcome, low total cost of care, and patient satisfaction goals. If you are a wound care professional or wound care manufacturer, now is the time to take advantage of this "opportunity" to participate in the parallel path of Medicare reimbursement: use your wound care skills, products, procedures, and services in the current PPS and take the lead in reinventing your practices, prod- 
ucts, and procedures to prepare for the future quality, cost of care, and patient satisfaction programs!

\section{ACKNOWLEDGMENTS AND FUNDING SOURCES}

No funding sources to acknowledge.

\section{AUTHOR DISCLOSURE AND GHOSTWRITING}

This author is the President of her own consulting firm, Kathleen D. Schaum \& Associates, Inc., and is the Director, Medical Products Reimburse- ment for Healthpoint Biotherapeutics. This article was written by its author.

\section{REFERENCES}

1. DMEPOS Competitive Bidding. Payment System. Available at www.cms.gov/Medicare/Medicare -Fee-for-Service-Payment/DMEPOSCompetitiveBid/ index.html (Accessed July, 2013).

2. Home Health Prospective Payment System. Available at www.cms.gov/Medicare/Medicare-Fee-for -Service-Payment/HomeHealthPPS/index.html (Accessed July, 2013)

3. Outpatient Prospective Payment System. Available at www.cms.gov/Medicare/Medicare-Fee-for-Service -Payment/HospitalOutpatientPPS/index.html (Accessed July, 2013).

4. Average Sales Price Drug Pricing File. Available at www.cms.gov/Medicare/Medicare-Fee-for-Ser vice-Part-B-Drugs/McrPartBDrugAvgSalesPrice/index .html (Accessed July, 2013)

5. Medicare Severity-Adjusted Diagnosis Related Group Payment Program. Available at www .cms.gov/Medicare/Medicare-Fee-for-Service -Payment/Hospice/index.html (Accessed July, 2013).

6. Medicare Physician Fee Schedule. Payment System. Available at www.cms.gov/Medicare/Medi care-Fee-for-Service-Payment/PhysicianFeeSched/ index.html (Accessed July, 2013).

7. Accountable Care Organizations. Prospective Payment System. Available at www.cms.gov/ Medicare/Medicare-Fee-for-Service-Payment/ACO/ index.html? redirect =/aco/ (Accessed July, 2013).

8. Pioneer Accountable Care Models. Available at http://innovation.cms.gov/initiatives/Pioneer-ACO -Model/ (Accessed July, 2013).
9. Advance Payment Accountable Care Model. Available at http://innovation.cms.gov/initiatives/ Advance-Payment-ACO-Model/ (Accessed July, 2013).

10. Medicare Shared Savings Program. Available at www.cms.gov/Medicare/Medicare-Fee-for-Service -Payment/sharedsavingsprogram/index.html?redir ect $=$ /sharedsavingsprogram/ (Accessed July, 2013).

11. Bundled Payments for Care Improvement Initiative. Available at http://innovation.cms.gov/ initiatives/bundled-payments/index.html (Accessed July, 2013)

12. Comprehensive Primary Care Initiative. Available at http://innovation.cms.gov/Files/fact-sheet/CPCl -Fact-Sheet.pdf (Accessed July, 2013).

\section{Abbreviations and Acronyms}

$\mathrm{ACO}=$ Accountable Care Organization

$\mathrm{APC}=$ Ambulatory Payment Classification

$A S P=$ average sales price

$\mathrm{BBA}=$ Balanced Budget Act

$\mathrm{BPCl}=$ Bundled Payments for Care Improvement Initiative

$\mathrm{CMS}=$ Centers for Medicare \& Medicaid Services

$\mathrm{CORF}=$ comprehensive outpatient rehabilitation facility

$\mathrm{CPC}=$ comprehensive primary care
$\mathrm{CPT}^{\circledR}=$ Current Procedural Terminology ${ }^{\circledR}$

[registered trademark

of the American Medical Association]

$\mathrm{DME}=$ durable medical equipment

DMEPOS $=$ durable medical equipment, prosthetics/orthotics, and supplies

$\mathrm{FFS}=$ fee-for-service

HCPCS $=$ Health Care Procedure Coding System

$\mathrm{HHA}=$ home health agency

$H H R G=$ home health resource group

HOPD = hospital-based outpatient wound care department

ICD-9-CM = International Classification of Diseases, Ninth Edition, Clinical Modification

IPPS = Inpatient Prospective Payment System

$\mathrm{LTCH}=$ long-term care hospital

$\mathrm{MAC}=$ Medicare Administrative Contractor

MDS $=$ minimum data set

MPFS = Medicare Physician Fee Schedule

MS-DRGs = Medicare Severity-Adjusted Diagnosis-Related Groups

OASIS = Outcome and Assessment Information Set

OPPS $=$ Outpatient Prospective Payment System

PPS = Prospective Payment System $\mathrm{QHP}=$ qualified healthcare professional

$R U G=$ resource utilization group $\mathrm{SNF}=$ skilled nursing facility 